УДК 662.997

\title{
ВНУТРЕННЯЯ ЭНЕРГИЯ ЗЕМЛИ: НОВАЯ ГИПОТЕЗА (ОБЗОР)
}

\author{
Басок Б.И., член-корр. НАН Украины, Базеев Е.Т., канд. техн. наук
}

Институт технической теплофизики НАН Украины, ул. Желябова, 2а, Киев, 03680, Украина

Наведено основні положення нещодавно опублікованої гіпотези щодо наявності в ядрі планети стабільного джерела геотермальної енергії, яке раніше не розглядалося, а саме: термоядерної реакції особливого класу (пікноядерної реакції). Мотивом появлення гіпотези стало знайдене у результаті розрахункових і експериментальних досліджень значне розходження даних енергетичного балансу Землі. Нові уявлення щодо природи геотермальної енергії дають підставу для уточнення концепції абіогенного походження вуглеводнів (нафти, природного газу).

Библ. 12, табл. 1.
Представлены основные положения недавно опубликованной гипотезы о существовании в ядре планеты стабильного, ранее не рассматриваемого, источника геотермальной энергии, а именно: термоядерных реакций особого класса (пикноядерных реакций). Мотивом появления гипотезы послужило обнаруженное в результате расчётных и экспериментальных изысканий значительное расхождение данных энергетического баланса Земли. Новые представления о природе геотермальной энергии дают основания для уточнения концепции абиогенного происхождения углеводородов (нефти, природного газа).
The article presents the main provisions of the recently published hypothesis about the existence in core of the planet a stable, not previously considered, the source of geothermal energy - the thermonuclear reactions of a special class (pycnonuclear reactions). The motive for the appearance of the hypothesis was the discovery as a result of the calculated and experimental research considerable divergence of the energy balance data of the Earth. New ideas about the nature of geothermal energy give rise to refine the concept of abiotic origin of hydrocarbons (oil, natural gas).

Ключевые слова: новая гипотеза, геотермальная энергия, земное ядро, термоядерные реакции, происхождение углеводородов.

Результаты проведенных в мире новых исследований тепловых потоков в недрах Земли, в том числе и экспериментальных, позволили по иному взглянуть на природу внутренней энергии планеты и явились мотивом появления гипотезы по уточнению природы геотермальной энергии [1]. Ниже представлен краткий обзор работ, послуживших обоснованию новой гипотезы, и основные положения гипотезы.

В настоящее время природа геотермальной энергии установлена и является общепризнанной - это следствие радиоактивного распада элементов, содержащихся в земной коре (радиоактивных изотопов, таких как $\left.{ }^{238} \mathrm{U},{ }^{235} \mathrm{U},{ }^{232} \mathrm{Th},{ }^{40} \mathrm{~K}\right)$. Рассматриваются гипотезы о наличии и других источников, генерирующих внутреннюю энергию Земли: приливное воздействие Луны, уплотнение мантии и др. [2].

Теоретическая (оценочная) величина теплового потока через земную поверхность определя- ется зависимостью [1]:

$F=d T / d r \lambda 4 \pi R 2$,

где $d T / d r=0,025 \ldots 0,030$ град/м (температурный коэффициент для глубины нескольких километров земной коры); $\lambda=2 \mathrm{BT} / \mathrm{M}$-град (коэффициент теплопроводности базальта верхнего слоя земной коры); $R$ - радиус Земли (6371 км). Из приведенного выражения получаем $F=(28 . .31)$ ТВт.

Для уточнения расчетной величины теплового потока с 1939 года начали проводить и экспериментальные исследования. Впечатляют масштабы практических экспериментов по определению локальных тепловых потоков через земную поверхность: 20 тысяч пунктов (неглубокие скважины с измерением температурных коэффициентов и теплопроводности) по всему земному шару, в том числе и под дном океанов.

Мотивом появления гипотезы послужили результаты недавно проведенных при участии 15 
университетов США, Западной Европы и Японии фундаментальных экспериментальных изысканий по определению величин тепловых потоков в недрах Земли, вызванных радиоактивным распадом вышеупомянутых изотопов. Обнаружилось значительное расхождение между количеством энергии, генерируемой вследствие распада радиоактивных изотопов, а также энергии других (нерадиоактивных) источников, и суммой количества энергии, необходимой для поддержания магнитного поля Земли, а также энергии излучения через земную поверхность. В таблице представлены расчётные и экспериментальные данные энергетического баланса Земли (в итоговые показатели не включены расчётные значения тепловых потоков).

Таблица. Энергетический баланс Земли (тепловые потоки, ТВт)

\begin{tabular}{|c|c|c|}
\hline \multicolumn{2}{|l|}{ Расход энергии } & Источник энергии \\
\hline $\begin{array}{l}\text { 1. Через поверхность Земли } \\
\text { расчёт: } \\
\text { эксперимент: } \\
\text { принимается: }\end{array}$ & $\begin{array}{l}28 \ldots 31[1] \\
30[2] \\
44,2 \pm 1[3] \\
46 \pm 3[4] \\
45 \pm 1[1]\end{array}$ & $\begin{array}{ll}\text { 1. Радиоактивный распад изотопов } \\
\text { расчет: } & 29-31[1] \\
\text { эксперимент: } & 20(238 \mathrm{U}, 232 \mathrm{Th})[5] \\
& 4(40 \mathrm{~K})[5]\end{array}$ \\
\hline $\begin{array}{l}\text { 2. Поддержание магнитного } \\
\text { оценивается: }\end{array}$ & $\begin{array}{l}\text { поля Земли } \\
85[1,6]\end{array}$ & $\begin{array}{l}\text { 2. Нерадиоактивные источники: } \\
\begin{array}{l}\text { уплотнение мантии и др. } \\
\text { оценивается: } 10 \text { [2] }\end{array}\end{array}$ \\
\hline Итого & 130 & Итого 34 \\
\hline
\end{tabular}

Методические сложности измерений [1] заставляют усреднять полученные результаты разными коллективами исследователей и тепловой поток через поверхность Земли принимается равным $45 \pm 1$ ТВт $\left(1,5 \times 10^{21}\right.$ Дж/год.). Эта энергия более чем на три порядка меньше энергии, получаемой Землёй от Солнца, хотя раньше, в XVIII веке, физики и климатологи считали, что климат зависит в основном от внутреннего тепла Земли. Недостающие по балансу 100 ТВт теплового потока (табл.) призван обеспечивать иной мощный источник стабильный энергии. Этим источником не может быть изначальный запас земной энергии ядра планеты, ибо вследствие теплопроводности земной коры и мантии он не мог бы сохраниться даже на протяжении 100 млн. лет. Температура ядра должна была бы существенно снизиться, но согласно последним исследованиям, температура внутреннего ядра Земли примерно на 1000 К выше, чем предполагалось ранее, и составляет $6250 \pm 500$ К [1].

Выдвинута гипотеза о существовании ранее не рассматриваемого источника внутренней энергии Земли [1]. Предположено, что таким источником внутренней энергии Земли могут быть термоядерные реакции особого класса (пикноядерные реакции) в ядре планеты. Показана принципиальная возможность их протекания при низких и сверхнизких температурах, но при очень высоких плотностях вещества, указаны необходимые показатели для таких реакций и оценены имеющиеся условия (топливо, температура и давление) в недрах планеты для их осуществления. Заметим, что температуры, охарактеризованы как “низкие и сверхнизкие", относительно температур, присущих термоядерным реакциям в разрабатываемых сейчас термоядерных энергоустановках или реакциях, вероятно, происходящим в недрах планет-гигантов.

В качестве топлива рассматривается водород в химическом соединении с различными металлами (гидриды) [7;8]. Растворённый в металлах водород имеется как во внешнем, так и во внутреннем ядре Земли. Необходимая температура для реакций составляет диапазон $10^{3}<\mathrm{T}<10^{5} \mathrm{~K}$. Температура в ядре Земли, как отмечалось выше, по уточнённым данным оценивается в $6250 \pm 500 К$. Необходимое давление для реакций $-10^{7} \ldots 10^{8}$ бар. Давление в ядре Земли составляет $3 \times 10^{6}$ бар, но при крупных землетрясени- 
ях (а их ежегодно бывает около 100) продольные сейсмические волны в локальных точках могут создавать давления в $10^{7} \ldots 10^{8}$ бар и более [1].

Таким образом, необходимые условия для протекания термоядерных (пикноядерных) реакций имеются. В отдельных местах ядра Земли, как центрах термоядерных реакций, происходит разложение гидридов металлов с выделением водорода и вынос избытка тепла с газо-водородными потоками во внешние сферы и слои, ближе к поверхности Земли. Эти водородно-флюидные потоки, возникающие в ядре, являются источником тепловой энергии, многократно превосходящей суммарную энергию радиоактивного распада вышеупомянутых изотопов и создающей тот недостающий тепловой поток в 100 ТВт в энергетическом балансе Земли (табл.)

Новые представления о термоядерной природе геотермальной энергии согласно выдвинутой гипотезе позволяют не только уточнить природу и величину внутренней энергии Земли, но и уточнить концепцию происхождение углеводородов (нефти, природного газа).

Как известно, в разные периоды (начиная со средних веков) учёные при выяснении генезиса углеводородов полагались на разнообразные гипотезы как органического (биогенного) так и неорганического (абиогенного) происхождения углеводородов, в частности, нефти [9].

Постепенно к 70-м годам XX века ведущие позиции заняло направление, отстаивающее биогенную природу нефти (Международные конгрессы нефти 1963, 1967 и 1971 годов). Поиски углеводородов в мире проводились, исходя из представлений их органического происхождения. И хотя абиогенное происхождение нефти не получило общепринятого признания, всё же и в дальнейшем взгляд на абиогенную природу происхождения нефти отстаивался и продолжает отстаиваться рядом учёных [1].

Описанная гипотеза о термоядерной природе внутренней энергии Земли представляет следующим механизм абиогенного происхождение углеводородов. «Восходящие водородно-флюидные потоки вымывают углерод из глубин геосфер, перемещая его в самые верхние оболочки литосферы. Проявление такой тенденции приводило к тому, что в осадочном чехле планеты и покры- вающих её водных бассейнах возрастала общая концентрация углерода, в результате формировались разнообразные соединения - от карбоновых толщин до скопления угля и углеводородов" [1]. При дегазации водорода из ядра планеты и при его попадании в обогащённые углеродом толщи будут протекать реакции гидрогенизации, формирующие нефтеносные слои и месторождения природного газа.

Новые представления о термоядерной природе внутренней энергии Земли позволяют уточнить существующие концепции о происхождении углеводородов и дают основания говорить об образовании нефти и газа в настоящее время и “до тех пор пока не иссякнут запасы водорода в земном ядре и не прекратятся термоядерные реакции"[1]. Не подтверждается ли это положение прогнозами постоянных сдвигов сроков обеспеченности запасов нефти и газа? Так, например, по прогнозу 1989 года срок обеспеченности запасов нефти составлял 41 год, природного газа - 58 лет [10]; прогноз 2012 года определяет такой срок соответственно в 40..45лет и 60...70 лет [11].

Не исключается также, что из ядра планеты может выходить и чистый водород через трещины и разрывы в земляной коре. Случаи выхода огромных количеств газов, содержащих водород и сам водород в чистом виде, геологам известны в прошлом [1]. Предложенная гипотеза даёт основание также рассматривать вопрос о возможности добычи чистого водорода из недр Земли. В этом случае для геологической науки может предстать проблема поиска и добычи водорода как топлива для промышленных целей.

Как отмечалось выше, в настоящее время превалирует концепция биогенного происхождения углеводородов. Рассмотренная гипотеза уточняет представления сторонников их неорганического происхождения, давая основание утверждать, что "в принципе могут существовать два равноправных источника углеводородов" [1]. При этом подчёркивается, что источники абиогенного происхождения углеводородов повсеместно распространены в Земле, в то время как биогенные источники ограничены по запасам и сосредоточены географически в местах распространения древней флоры и фауны.

В Институте геологических наук НАН Украи- 
ны проведены исследования, результаты которых меняют представления о ресурсном потенциале земных недр и, возможно, подтверждают абиогенную природу происхождения углеводородов. "Были получены реальные доказательства формирования зон интенсивного эндогенного рудообразования и нефтегазонакопления суперглубинных флюидов, связанных не только с верхней мантией, а и с нижней мантией и границей мантии и ядра. Это удалось сделать благодаря системному комплексному подходу к проблеме на основании результатов сейсмографических и разных минералогогеохимических исследований. Подъём флюидов из глубин геосферы Земли было независимо подтверждено открытием нового явления - наличия микро- и наночастиц самородных металлов и природных сплавов в коллекторах нефти и газа, в геотермальных рудах и т. п. Это коренным образом меняет наши представления о ресурсном потенциале земных недр и о закономерности нефтедогенеза и рудообразования. Три нефтегазоносных региона на территории Украины относятся к сверхглубоким осадочным бассейнам с аномально высокими мощностями осадочного типа. Глубокие горизонты этих бассейнов являются неисчерпаемыми источниками углеводородов, водорода, гелия, в т. ч. ${ }^{3} \mathrm{He}$. Их освоение - это без преувеличения будущее нашей цивилизации" [12].

Как заключение отметим, что гипотеза о термоядерной природе внутренней энергии Земли носит дискуссионный характер. Представляется интересным проследить дальнейший ход обсуждения этой проблемы.

\section{ЛИТЕРАТУРА}

1. Терез Э.И., Терез И.Э. Реакция синтеза основной источник внутренней энергии Земли
// Вестник Российской академии наук. - 2015. T. 85, №3.- С.240-246.

2. Anderson D.L. New Theory of the Earht. N.Y.: Cambridge U. Press, 2007.

3. Pollak H.N., Hurter S.J., Johnson J.R. Heat Flow from the Earth's Interior: Analysis of the Global Data Set // Reviews of Geophysics. 1993. № 3 .

4. Lay T., Hernlund J., Buffet B.A. Core-mantle boundary heat flow// Nature Geoscience. 2008. V. 1. P 25-35.

5. Condo A., Condo Y., Ichimura K., et al. Partial Radiogenic Heat Model for Earth Revealed by Geoneutrino Measurements// Geoscience. 2011. V. 4. P.647-651.

6. Баранов М.И. Приближённый расчёт магнитного поля Земли // Электротехника и электроника. 2010. - Т.6. С.46-48.

7. Ларин В. Н. Гипотеза изначально гидридной Земли. М.: Недра, 1980.

8. Терез Э. И., Терез . И. Э. Термоядерные процессы в ядре - главный источник энергии геодинамической эволюции и дегазации Земли // Известия Крымской астрофизической обсерватории . 2011. - № 1.

9. Енергетика: історія, сучасність і майбутнє. Т.1. Від вогню та води до електрики.- К., 2006. 304c. Розділ 8. Нафта і газ. С.199-207.

10. Вольфберг Д. Б., Троиикий А. А. Основные итоги XIV конгресса Мировой энергетической конференции // Теплоэнергетика. 1990. № 2. C.2-8.

11. Кондратов Д. И. Проблемы мирового рынка // Вестник РАН. 2015. Т. 85. № 7. - С. 616-626.

12. Із зали засідань Президії НАН України 2 грудня 2015 року//Вісник НАНУ. 2016. № 2. C.13-17. 


\section{INTERNAL ENERGY OF THE EARTH: A NEW HYPOTHESIS (OVERVIEW)}

\section{Basok B.I., Bazyeev E.T.}

Institute of Engineering Thermophysics of the National Academy of Sciences of Ukraine, vul. Zhelyabova, 2a, Kyiv, 03680, Ukraine

The article presents the main provisions of the recently published hypothesis about the existence in core of the planet a stable, not previously considered, the source of geothermal energy - the thermonuclear reactions of a special class (pycnonuclear reactions). The motive for the appearance of the hypothesis was the discovery as a result of the calculated and experimental research considerable divergence of the energy balance data of the Earth. New ideas about the nature of geothermal energy give rise to refine the concept of abiotic origin of hydrocarbons (oil, natural gas).

References 12, tables 1.

Key words: hypothesis, source of geothermal energy, thermonuclear reactions, concept of abiotic origin of hydrocarbons.

1. Terez E.I., Terez I.E. Reaction of Synthesis is a Major Source of the Earth's Internal Energy. Vestnik RAN. - 2015. - T. 85, №3. - P.240 - 246.

2. Anderson D.L. New Theory of the Earth. N.Y.: Cambridge U. Press, 2007.

3. Pollak H.N., Hurter S.J., Johnson J.R. Heat
Flow from the Earth's Interior: Analysis of the Global Data Set. Rewiews of Geophysics. 1993. №3.

4. Lay T., Hernlund J., Buffer B.A. Core-mantle Boundary Heat Flow. Nature Geoscience. 2008. V. 1. P.25-35.

5. Condo A., Condo Y., Ichimura K., et al. Partial Radiogenic Heat Model for Earth Revealed by Geoneutrino Measurements. Geoscience. 2011. V.4. P.647-651.

6. Baranov M.I. An Approximation Calculation of the Earth's Magnetic Field. Elektrotechnika i elektronika. 2010. - T. 6. P.46-48.

7. Larin V.N. Hydridic Earth Theory. M.: Nedra, 1980.

8. Terez E.I., Terez I.E. Thermonuclear Processes in the Core - the Main Source of Energy of the Geodynamic Evolution and Degassing of the Earth. Izv. Krymskoj astrofisicheckoj observatorii. 2011. №1.

9. Energy: Past, Present and Future. V.1. From Fire and Water to Electricity. - K. 2006. - 304 p. Rozdil 8. Nafta i gas. P.199-207.

10. Wolfberg D.B., Troickij A.A. The Main Results of the Congress of the World Energy Conference. Teploenergetika. 1990. - №2. - P.2-8.

11.Kondratov D.I. The Problems of the World Market. Vestnik RAN. 2015. - T. 85. №7. - P.616626.

12.From the meeting room of NAS Ukraine December 2, 2015. Visnyk NANU. 2016. - №2 . P.13-17.

Получено 16.06.2016 Received 16.06.2016 